\title{
Gastroesophageal reflux disease in COPD: links and risks
}

\author{
This article was published in the following Dove Press journal: \\ International Journal of COPD \\ 14 September 2015 \\ Number of times this article has been viewed
}

\author{
Annemarie L Lee ${ }^{1-3}$ \\ Roger S Goldstein 1,2,4 \\ 'West Park Healthcare Centre, \\ ${ }^{2}$ Department of Physical Therapy, \\ University of Toronto, Toronto, ON, \\ Canada; ${ }^{3}$ Institute for Breathing and \\ Sleep, Austin Hospital, Melbourne, VIC, \\ Australia; ${ }^{4}$ Department of Medicine, \\ University of Toronto, Toronto, ON, \\ Canada
}

\begin{abstract}
COPD is a long-term condition associated with considerable disability with a clinical course characterized by episodes of worsening respiratory signs and symptoms associated with exacerbations. Gastroesophageal reflux disease (GERD) is one of the most common gastrointestinal conditions in the general population and has emerged as a comorbidity of COPD. GERD may be diagnosed by both symptomatic approaches (including both typical and atypical symptoms) and objective measurements. Based on a mix of diagnostic approaches, the prevalence of GERD in COPD ranges from $17 \%$ to $78 \%$. Although GERD is usually confined to the lower esophagus in some individuals, it may be associated with pulmonary microaspiration of gastric contents. Possible mechanisms that may contribute to GERD in COPD originate from gastroesophageal dysfunction, including altered pressure in the lower esophageal sphincter (which normally protect against GERD) and changes in esophageal motility. Proposed respiratory contributions to the development of GERD include respiratory medications that may alter esophageal sphincter tone and changes in respiratory mechanics, with increased lung hyperinflation compromising the antireflux barrier. Although the specific cause and effect relationship between GERD and COPD has not been fully elucidated, GERD may influence lung disease severity and has been identified as a significant predictor of acute exacerbations of COPD. Further clinical effects could include a poorer health-related quality of life and an increased cost in health care, although these factors require further clarification. There are both medical and surgical options available for the treatment of GERD in COPD and while extensive studies in this population have not been undertaken, this comorbidity may be amenable to treatment.
\end{abstract}

Keywords: COPD, GERD, pulmonary aspiration, treatment

\section{Introduction}

COPD is a chronic, progressive condition, characterized by an increased inflammatory response within the airways and airflow limitation that is not fully reversible. ${ }^{1}$ The clinical profile is frequently punctuated by acute exacerbations, ${ }^{2}$ which increase the risk of morbidity and mortality of $\mathrm{COPD}^{3}$ and are linked to worsening quality of life and accelerated decline in lung function. ${ }^{4}$ The prevalence of COPD is continually rising, ${ }^{5}$ particularly in those aged 65 years and older. Accompanying the clinical profile of COPD is a range of comorbidities, which have the potential to complicate the clinical presentation of this condition and may influence morbidity and mortality.

Gastroesophageal reflux disease (GERD) develops when the reflux of gastric contents results in troublesome symptoms or complications. ${ }^{6}$ It is a common upper gastrointestinal condition, affecting up to $33 \%$ of the general population ${ }^{7}$ and may be associated with either esophageal or extra-esophageal syndromes. ${ }^{6}$ Refluxate may be acidic or nonacidic (alkaline), liquid, or gaseous. ${ }^{8}$ The frequency and duration of episodes of reflux as well as the destination of the gastroesophageal refluxate affect the impact of GERD. 
As both GERD and COPD are highly prevalent conditions, the possibility of an interaction has long been recognized..$^{9-12}$ With the potential for GERD to aggravate the clinical status of COPD and of the mechanical changes associated with COPD to exacerbate GERD, it is important to understand the relationship and possible consequences of the two conditions co-occurring. This review will explore the underlying pathophysiology of GERD, the commonly applied diagnostic tools, its prevalence and clinical presentation as well as risk factors, and current management strategies.

\section{Gastroesophageal reflux disease Pathophysiology}

Gastroesophageal reflux (GER) is a normal physiological occurrence, and the integrity of the gastroesophageal junction influences the occurrence and frequency of GER events. Physiologically, there are four causes of GER of gastrointestinal origin. The most common trigger is transient, spontaneous relaxation of the lower esophageal sphincter (LES), ${ }^{13}$ which may occur in both an upright or recumbent position ${ }^{14}$ and promotes reflux. GER may also occur due to diminished basal LES pressure, ${ }^{15}$ as a result of straining or free reflux. Straininduced reflux occurs when a hypotensive LES is overcome by an abrupt increase in intra-abdominal pressure (eg, during bending). ${ }^{16}$ Free reflux occurs when the basal LES pressure is within 1-4 $\mathrm{mmHg}$ of the intragastric pressure; this small pressure gradient heightens the likelihood of GER. ${ }^{15} \mathrm{~A}$ hiatus hernia is displacement of the gastroesophageal junction above the diaphragm. ${ }^{17}$ The pressure gradient between the thorax and the abdomen promotes the movement of gastric contents into the esophagus. ${ }^{18}$ Transient LES relaxations are more likely to be followed by GER episodes in the presence of a hiatus hernia. Normally, esophageal peristalsis facilitates esophageal clearance following reflux episodes. ${ }^{19}$ Peristaltic dysfunction, with absent or low-amplitude contractions in the distal esophagus, which can be detected through manometry studies, contributes to prolonged esophageal clearance, which increases the chance of reflux. ${ }^{20}$ The diagnosis of GERD should be considered when symptoms associated with these physiological changes are reported by the patient. ${ }^{6}$

Changes in LES tone are often triggered by lifestyle factors such as stress or by the consumption of specific foods, including products high in fat (delayed gastric emptying) or those that lower the LES pressure (chocolate, peppermint, onion, garlic, caffeine, and alcohol). ${ }^{21}$ Eating or drinking acidic foods (tomato products, citrus, and carbonated beverages) may trigger symptoms. ${ }^{21}$ Other lifestyle factors include sleeping in a supine position or consumption of a meal immediately before sleeping; both may be linked to nocturnal awakening from symptoms. ${ }^{21}$

\section{Clinical presentation}

Typical symptoms of GERD include heartburn, acid regurgitation, ${ }^{22}$ chest pain, ${ }^{23}$ epigastric pain, or sleep disturbances. ${ }^{6}$ These clinical features together with esophageal complications, including reflux esophagitis, Barrett's esophagus, and adenocarcinoma are collectively referred to as esophageal syndromes. ${ }^{24}$ Symptoms such as chronic cough or laryngitis that occur secondary to reflux are classed as extra-esophageal syndromes. An outline of typical and atypical clinical presentations of GERD is presented in Figure 1. Either may be present in COPD.

\section{Diagnostic tools Diagnosis of GERD}

The most common approach to the diagnosis of GERD is through an accurate medical history, enquiring about typical GERD symptoms and their relationship to food, posture, and stress. ${ }^{21}$ It is important to be aware that symptoms of GERD may be similar to some symptoms of COPD. Therefore, it is necessary to enquire as to the timing of the GERD symptoms and their association with awakening from sleep, the use of respiratory inhalers in association with GERD symptoms, or the presence of respiratory symptoms after meals. Further evaluation may include symptomatic assessment through validated questionnaires, which ideally incorporate both typical and atypical symptoms. ${ }^{25,26}$ In the presence of symptoms, an empirical trial of acid suppression therapy is often undertaken, with resolution of symptoms considered clinically indicative of GERD, provided the patient has been symptomatic. ${ }^{27}$ If symptoms are present, objective tools such as esophageal endoscopy may be used to identify secondary complications of mucosal injury and esophagitis..$^{28,29}$

If asymptomatic reflux is suspected, alternative options for diagnosing GERD include ambulatory 24-hour esophageal pH monitoring. This is the current "gold standard" for diagnosing GERD. ${ }^{30-33}$ Dual-channel monitoring measures proximal and distal esophageal $\mathrm{pH}$, giving a comprehensive profile of GERD ${ }^{34}$ using well-defined criteria. ${ }^{31,35}$ Via a small catheter positioned in the esophagus, this technique measures the esophageal luminal $\mathrm{pH}$. The frequency and duration of reflux episodes and the proximal spread of the refluxate over a complete circadian cycle are quantified. ${ }^{35}$ For distal GERD, sensitivity ranges from $81 \%$ to $96 \%$ with specificity from $85 \%$ to $100 \%{ }^{30-33}$ For proximal GERD, the sensitivity ranges from $55 \%$ to $86 \%$, although the specificity is slightly higher 


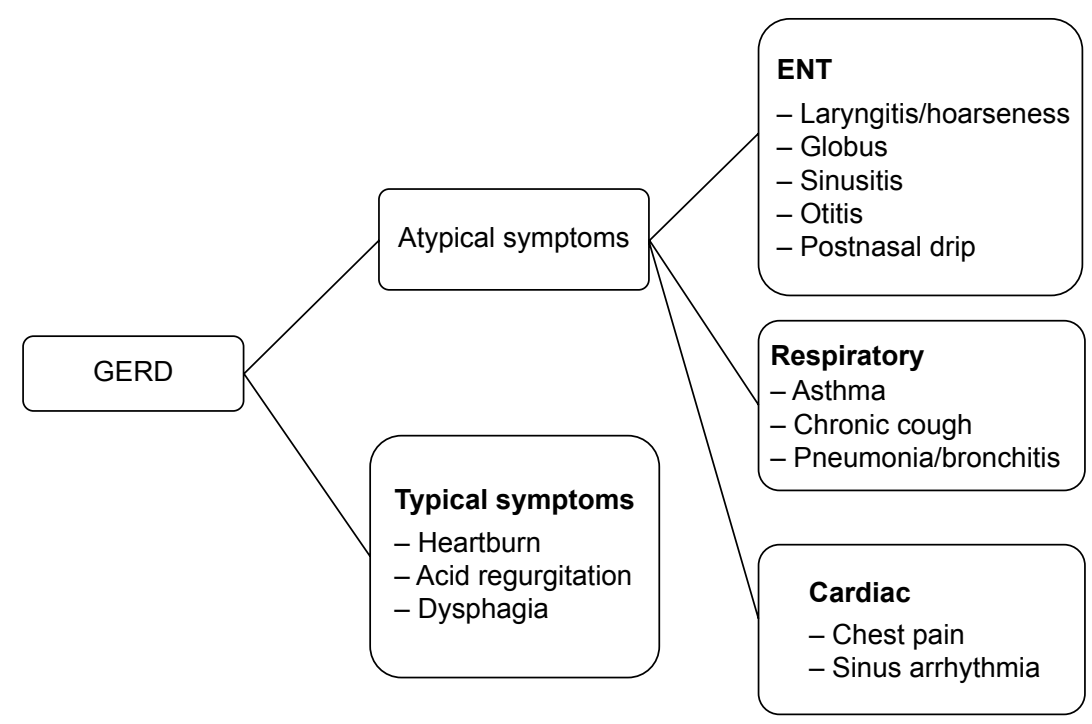

Figure I Typical and atypical clinical presentations of GERD.

Abbreviations: GERD, gastroesophageal reflux disease; ENT, ears-nose-throat.

$(80 \%-91 \%) .{ }^{36,37} \mathrm{~A}$ variation on this is telemetry capsule $\mathrm{pH}$ monitoring, which offers increased patient tolerability and the option to extend the monitoring period to 48 hours or 96 hours. ${ }^{38}$ With the identification of both acid and nonacid reflux, together with the mixture of gas and liquid reflux, combined multichannel intraluminal impedance and $\mathrm{pH}$ monitoring records GERD at all $\mathrm{pH}$ levels. ${ }^{39}$ It quantifies volume and gas reflux and the air-liquid composition of the refluxate, giving an exact assessment of the proximal extent of refluxed material and a detailed characterization of each reflux episode..$^{8,39,40}$

\section{Diagnosis of pulmonary microaspiration of gastric contents}

Pulmonary microaspiration of gastric contents can be detected through various methods. Proximal esophageal $\mathrm{pH}$ monitoring has been considered a surrogate marker. ${ }^{10,41,42}$ One of the more novel measures of pulmonary microaspiration is the measurement of pepsin in airway samples. Pepsin is secreted by cells unique to the gastric mucosa as pepsinogen I or $\mathrm{II}^{43,44}$ and requires acidic conditions to be converted to active pepsin. The detection of pepsin in pulmonary secretions is suggested to indicate pulmonary microaspiration of gastric contents. ${ }^{45}$ Pepsin has been detected in bronchoalveolar lavage of lung transplant recipients who demonstrated GERD on esophageal $\mathrm{pH}$ monitoring or impedance monitoring ${ }^{45-48}$ and more recently in sputum ${ }^{44,49}$ and exhaled breath condensate $(\mathrm{EBC})^{50}$ in individuals with COPD. $\mathrm{EBC}$ is a sample of breath water vapor containing pulmonary epithelial lining fluid. Acidification of the hypopharynx can occur when gastric contents reach beyond the upper esophageal sphincter (UES), which can be reflected by the presence of pepsin or lower $\mathrm{pH}$ levels in EBC. ${ }^{51}$

\section{Prevalence of GERD in COPD}

The prevalence of GERD in individuals with COPD has been explored in a number of studies. ${ }^{11,41,42,49,52-57}$ A range of diagnostic tools have been used, including symptom questionnaires and objective measurements, outlined in Table 1. Based on self-reported symptoms and questionnaires, the prevalence of GERD ranges from $17 \%$ to $54 \% .^{12,52-55,57-61}$ Variation is partially attributable to the heterogeneity of questionnaire content. However, while typical GERD symptoms exhibit a sensitivity of $90 \%$, the specificity is as low as $47 \%,{ }^{10}$ which may limit their diagnostic value.

By comparison, according to esophageal $\mathrm{pH}$ monitoring, the prevalence ranges from $19 \%$ to as high as $78 \%$. $^{11,41,42,49,56,62,64}$ Such a wide spread is related to several factors, including the differing GERD criteria applied ${ }^{31,34,65,66}$ and whether the test was undertaken on or off antireflux medication. Mixed patterns of reflux are evident, with distal reflux only, proximal reflux only, and a mix of both demonstrated. ${ }^{11,49,56,62}$ In those with COPD, the prevalence is five times greater than the non-COPD population for proximal and distal reflux. ${ }^{7,67}$ GERD can affect patients with moderate to very severe COPD. ${ }^{41,42,49,56,62,68}$ Although a detailed clinical history of symptom presentation is recommended, ${ }^{69}$ this method of diagnosis is reliant upon the provocation of symptoms by reflux events, which in the event of asymptomatic (clinically silent) reflux is not a reliable 


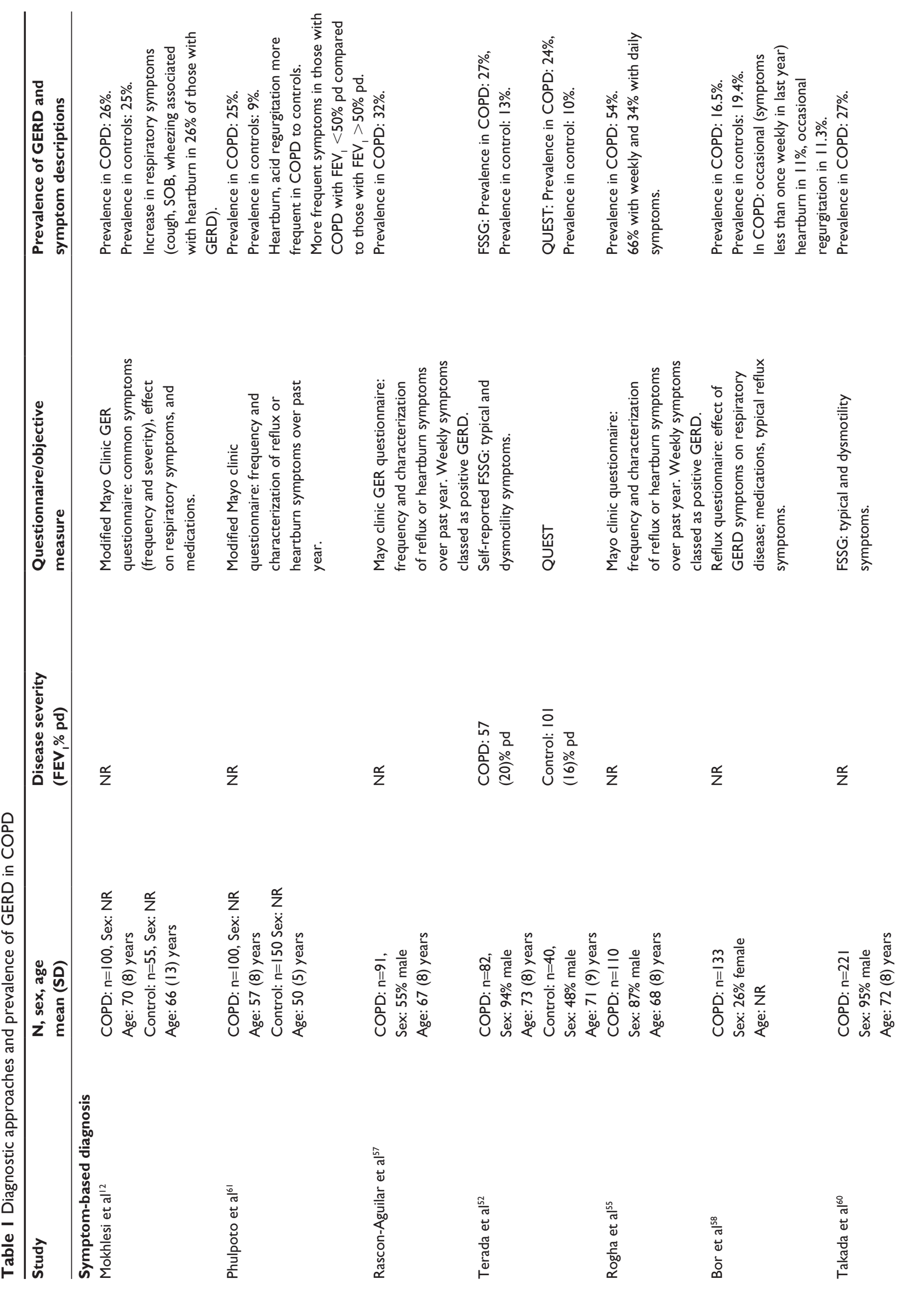



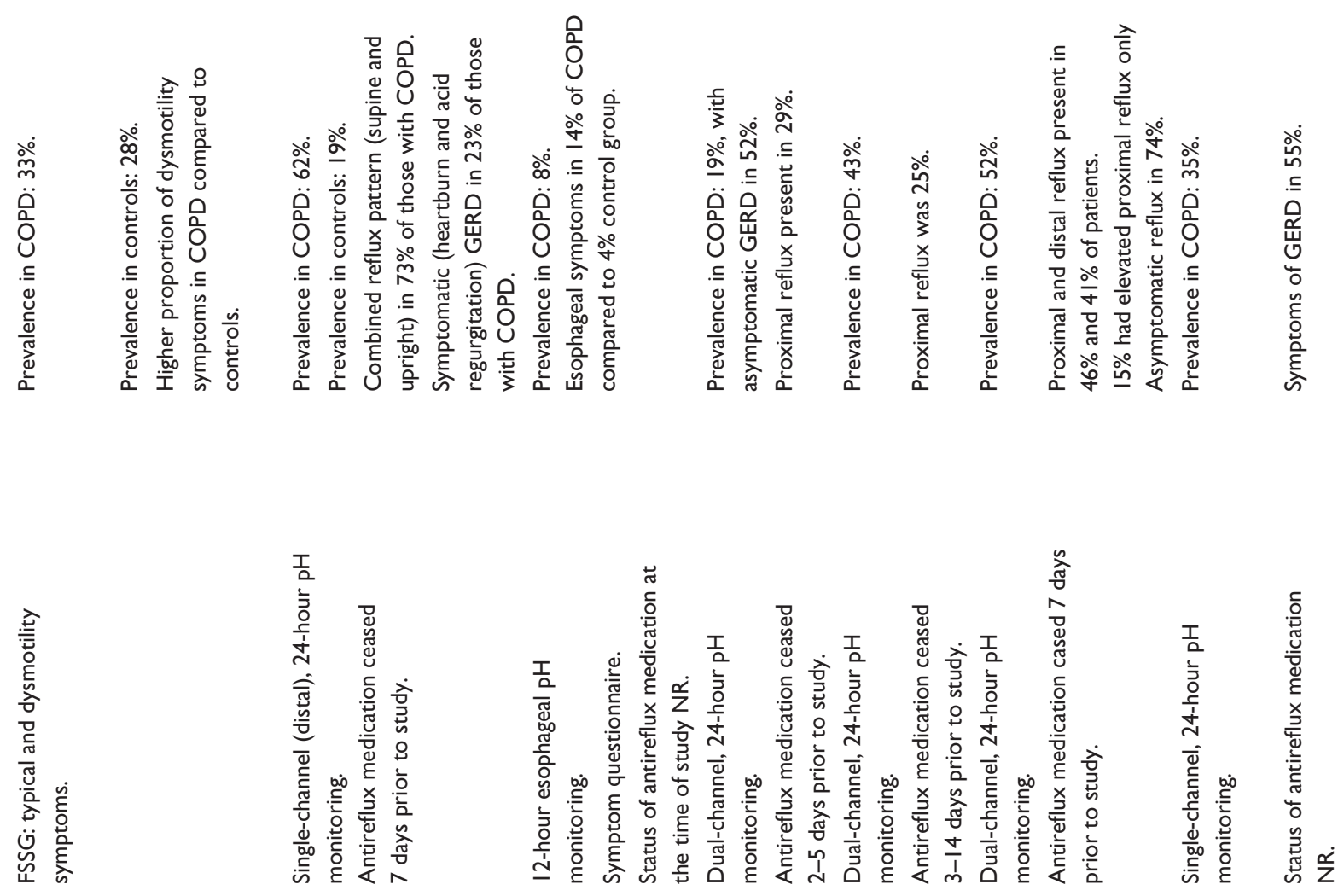

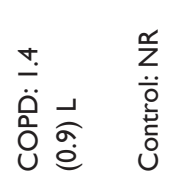

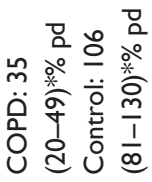

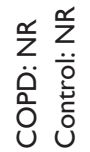

ㅁ
$\stackrel{\circ}{a}$
d
$\circ$

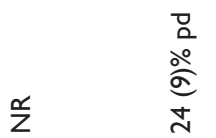

$\stackrel{\aleph}{z}$

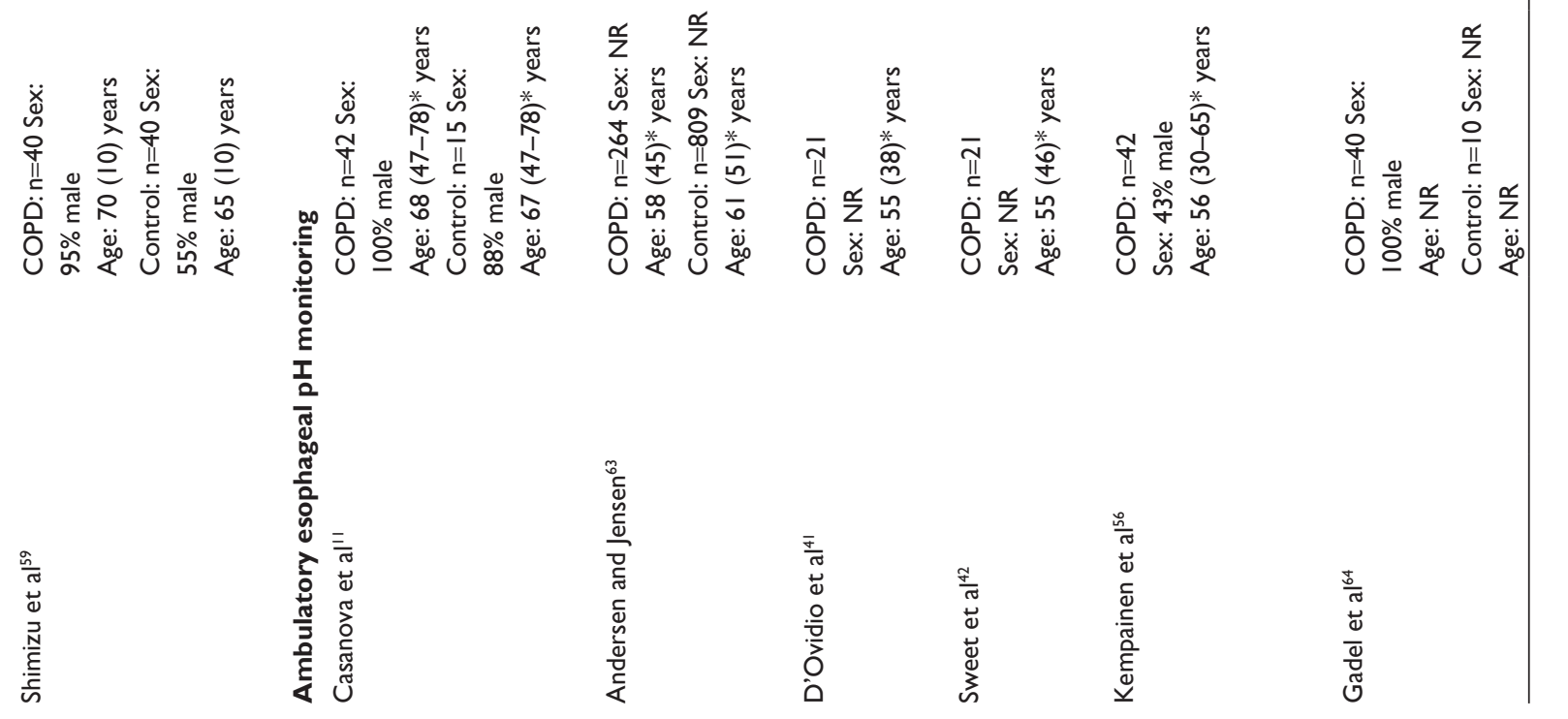




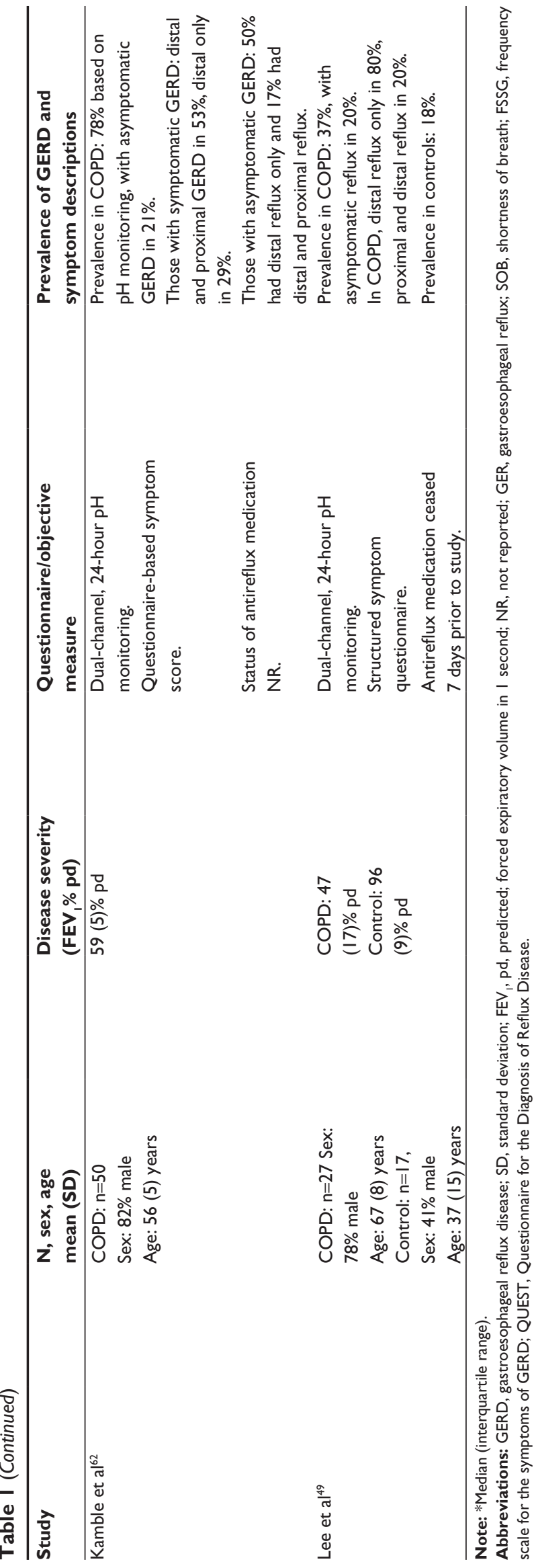

indicator. The presence of asymptomatic reflux (20\%-74\%) in $\mathrm{COPD}^{11,41,49,56,62}$ emphasizes the importance of objective confirmation of GERD in some individuals.

The cause and effect relationship between COPD and GERD has been reported through case-control and cohort studies. El-Serag and Sonnenberg ${ }^{70}$ in a case-control study found that a higher risk of esophageal disease was evident in those with COPD compared to controls (odds ratio [OR] $1.43,95 \%$ confidence interval [CI $] 1.33-1.53) . .^{70} \mathrm{~A}$ recent longitudinal cohort study followed two groups of patients, those diagnosed with GERD with no previous history of COPD and those diagnosed with COPD with no history of GERD over 5 years. ${ }^{71}$ In those with GERD, the incidence of COPD was with a risk ratio of 1.17 (95\% CI 0.91-1.49). In those with COPD, the incidence of GERD was 14.9 cases per 1,000 (95\% CI 13.9-16.0), with a relative risk of 1.49 (95\% CI 1.19-1.78). While this suggests that a diagnosis of COPD may predispose patients to developing symptoms of GERD, the reasons require further clarification.

One possible explanation is the effect of smoking, and in particular, nicotine on esophageal sphincter tone and esophageal clearance. Smoking has been associated with a reduction in LES tone, believed to be secondary to nicotine-induced relaxation of the circular muscle of the LES ${ }^{72}$ and reflected by the increased acid exposure in the upright position and an increased frequency of reflux events $>5$ minutes in duration. ${ }^{73}$ Prolonged acid clearance secondary to diminished salivation, which may persists for $>6$ hours after smoking, has also been reported to result in reduced neutralization of esophageal reflux by swallowed saliva. ${ }^{72} \mathrm{With}$ nicotine levels persisting for at least 6 hours after smoking, the implication is that the drug effect may last for a similar duration. ${ }^{72} \mathrm{~A}$ higher severity of GERD has been demonstrated in those with COPD who have a high smoking index, ${ }^{64}$ and pack-years has been found to be an independent risk factor for GERD (OR 1.015 [95\% CI 1.004-1.025]). ${ }^{74}$ Smoking is a risk factor for GERD in the general population, ${ }^{75}$ and this together with smoking being a leading cause of $\mathrm{COPD}^{76}$ suggests that smoking and the associated effects of nicotine may contribute to GERD in COPD.

\section{Presence of pulmonary microaspiration in GERD}

Surrogate indicators of pulmonary microaspiration of gastric contents have been examined in COPD. Pepsin in sputum samples was detected in $33 \%$ of individuals with moderate-to-severe COPD. ${ }^{49}$ Although no significant association between esophageal $\mathrm{pH}$ monitoring indices and 
pepsin concentrations in sputum was evident, this has been previously observed in individuals with other types of lung disease. ${ }^{44,46,77,78}$ Briefly, isolated reflux events that could be aspirated may be insufficiently frequent to contribute to the criteria defining GERD. Laryngopharyngeal reflux, based on laryngeal examination and symptom questionnaires, has also been detected in $44 \%$ of individuals with COPD. ${ }^{79}$ A pilot study of EBC in ten individuals with COPD found pepsin in 70\%, irrespective of a diagnosis of GERD based on esophageal $\mathrm{pH}$ monitoring. ${ }^{80}$ Lower $\mathrm{EBC} \mathrm{pH}$ has been related to severe GERD symptoms in COPD, ${ }^{52}$ although there was no significant correlation between EBC $\mathrm{pH}$ and sputum inflammatory indices (tumor necrosis factor- $\alpha$ and interleukin-8). This suggests that EBC $\mathrm{pH}$ may reflect acid reflux rather than tracheobronchial inflammation. Greater clarity is required to determine the optimal frequency and timing of EBC collection necessary for it to be included as an index of acid reflux.

\section{Possible contributing factors to GERD in COPD Gastroesophageal mechanisms}

A number of possible mechanisms originating from a gastrointestinal or respiratory perspective may increase the vulnerability to GERD in those with COPD. Although esophageal motility studies have not been extensively applied, reduced daytime and nocturnal esophageal peristalsis ${ }^{40,56,81}$ and a decrease in $\mathrm{UES}^{82,83}$ and LES pressure has been demonstrated in those with severe COPD. ${ }^{11,40,64,82}$ Change in LES pressure may be partially attributed to smoking and the effects of nicotine. ${ }^{72}$

Other possible explanations for pulmonary aspiration secondary to GERD are related to swallowing dysfunction in COPD. Precise coordination between swallowing and respiration is necessary, with the swallowing reflex an important defense against airway infection and aspiration. ${ }^{83}$ Compared to healthy controls, the swallowing reflex can be impaired in $\mathrm{COPD},{ }^{84}$ with a lack of coordination of the pharyngeal musculature and disruption of the breathing-swallowing coordination. ${ }^{85-87}$ Patients are more likely to swallow during inhalation or inhale directly after swallowing, as respiratory requirements take precedence over swallowing. ${ }^{85}$ Low subglottic air pressure occurs during early inhalation, late exhalation, or at the transition point between exhalation and inhalation. If swallowing takes place during times of subglottic air pressure, the physiology of swallowing can also be altered. If the preferred pattern of exhale-swallow-exhale is altered, the risk of aspiration increases. ${ }^{86}$ This may be a contributing factor to exacerbations of COPD, illustrated by a greater frequency of annual exacerbations (OR 4.86 [95\% CI 1.45-18.43]) in individuals with an abnormal swallowing reflex. ${ }^{83}$ In turn, exacerbations of COPD, with altered respiratory demands, may increase the risk of further aspiration. ${ }^{86}$

\section{Respiratory mechanisms}

Both alterations in respiratory mechanics and side effects of respiratory medications could contribute to GERD. Severe hyperinflation requires increased respiratory muscle inspiratory effort to overcome the increased inspiratory load at high lung volume. The resulting increase in negative pressure amplifies the pressure gradient between the thorax and abdomen, which impacts on LES tone and predisposes to reflux..$^{88,89}$ This may be especially present during COPD exacerbations when reductions in airflow together with increased coughing impact on this pressure gradient. Airflow obstruction significantly increases the frequency of transient LES relaxation, a mechanism documented in asthma. ${ }^{90}$ In stable COPD, although differences in lung mechanics between those with and without GERD were not apparent, ${ }^{11}$ a negative correlation between LES and UES pressure and indices of hyperinflation has been described. ${ }^{64}$ To date, the association between airway obstruction and LES relaxation requires further clarity. ${ }^{90}$ The reduction in LES tone secondary to smoking together with coughing, a common symptom of COPD, may predispose some individuals with COPD to strain-induced acid reflux. ${ }^{72}$ Heightened anxiety is known to aggravate GERD symptoms by increasing acid production. ${ }^{91}$ As increased anxiety is common in COPD,${ }^{1}$ this may be an additional contributory factor to GERD.

\section{Respiratory medications}

Respiratory medications, including beta agonists, anticholinergics, corticosteroids, and theophylline preparations have been proposed as possible factors that may be related to GERD. ${ }^{53,92-98}$ While these medications may alter esophageal function by reducing LES pressure or esophageal motility, ${ }^{92-94}$ their specific contribution to the risk of GERD is variable. Some studies observed that a greater proportion of individuals with COPD (stable or those at risk of an exacerbation) and GERD were prescribed inhaled corticosteroids, shortand long-acting beta ${ }_{2}$ agonists, and combination therapy (inhaled corticosteroids/long-acting beta ${ }_{2}$ agonists); ${ }^{53,59}$ others found no difference in the prescription of these respiratory medication classes and the presence/absence of GERD. ${ }^{12,54,55,57,58,60,74}$ Although it has been hypothesized that these classes of medications may contribute to GERD, the 
nature of this relationship in COPD has not been fully determined. An increased use of anticholinergics in those with COPD and GERD has been reported by Garcia Rodriguez et $\mathrm{al}^{71}$ while another study found no difference. ${ }^{94}$ Although central and peripherally acting anticholinergics can reduce LES pressure, their antitussive effect can encourage cough suppression and may minimize the occurrence of changes in intra-abdominal pressure, which may predispose GERD. ${ }^{94}$ It has been suggested that those with GERD may require more intense bronchodilator therapy secondary to increased severity of respiratory symptoms and exacerbations. ${ }^{53}$ The increased use of bronchodilator therapy when reflux symptoms are experienced lends support to a possible association between reflux events and worsening symptoms. ${ }^{12}$ The association between GERD and respiratory medications may also be a reflection of the severity of lung disease rather than the specific physiological effects of these medications on esophageal function. Further exploration of the cause and effect relationship between respiratory medications and GERD in COPD is warranted.

\section{Non-COPD specific factors}

A mix of demographic factors may increase the risk of GERD in COPD. Older age ( $>60$ years) is often a factor, ${ }^{53,58,64,95,99}$ with an increased risk (OR 3.7 [95\% CI 2.4-5.9]) reported in those over 70 years. ${ }^{71}$ Given the high proportion of COPD patients aged over 65 years, this finding is not surprising. The contribution of sex is variable, with some studies finding females at greater risk, ${ }^{53}$ others demonstrating that GERD is more common in males ${ }^{71}$ and some finding no difference. ${ }^{54,58}$ This is consistent with studies of GERD among the general population $^{100,101}$ and leaves open the influence of sex as an independent risk factor for GERD.

A larger body mass index (BMI; $>25 \mathrm{~kg} / \mathrm{m}^{2}-$ classed as overweight) has been identified as a risk for GERD in COPD, ${ }^{53-56,58,64}$ a risk which increases as BMI increases. ${ }^{53}$ For those with severe COPD, a higher BMI was a predictor for GERD (OR 1.2 [95\% CI 1.0-1.6]). ${ }^{56}$ While the BMI of participants in these studies did not meet the criteria for obesity $\left(>30 \mathrm{~kg} / \mathrm{m}^{2}\right)$, a greater BMI impacts on the contour of the diaphragm and will influence the elastic work of breathing. ${ }^{21}$ When combined with respiratory-related risk factors, this may increase the contribution of a higher BMI to GERD in COPD. The prediction of a higher BMI being a contributing factor is not unexpected, given that it is identified as a common contributing factor in the general population. ${ }^{102}$

Other comorbidities, including cardiac disease and obstructive sleep apnea, have also been associated with a heightened risk of GERD. ${ }^{53}$ In those with obstructive sleep apnea, increased intrathoracic pressure during apneic episodes is accompanied by increased transdiaphragmatic pressure, which encourages migration of gastric contents up the esophagus. ${ }^{103}$ The repetitive pressure changes also contribute to LES insufficiency. ${ }^{103}$ Whether they are independent variables or common consequences of poor diet and obesity remains to be established. ${ }^{104}$

\section{Influence of GERD on COPD severity}

Two of the possible mechanisms by which GERD may impact on the severity of COPD are vagally mediated reflex bronchoconstriction and pulmonary microaspiration. ${ }^{105}$ Vagally mediated reflex bronchoconstriction originates from the shared autonomic innervation between the tracheobronchial tree and the esophagus. The presence of esophageal acid in the distal esophagus stimulates airway irritation and an inflammatory response, with the release of potent mediators of bronchoconstriction. ${ }^{106}$ The second mechanism by which GERD may impact on respiratory disease is pulmonary microaspiration. During microaspiration, refluxed gastric material extends proximally to the esophagus and then enters the hypopharynx, directly triggering a laryngeal or tracheal response, which may manifest as coughing, wheezing, or a sensation of dyspnea. ${ }^{105}$

The relationship between the severity of COPD based on measures of lung function and GERD is controversial, with studies demonstrating mixed results. Some studies observed no significant relationship between GERD and pulmonary function, based on dynamic and static lung volume measurements or pulmonary resistance, $, 11,12,49,56,57,96,107$ whereas other studies found poorer lung function in those with GERD symptoms who had more severe lung disease. ${ }^{12,55}$ The correlation between oxygen desaturation and nocturnal episodes of distal reflux suggests that GERD may influence nocturnal respiratory status in some patients. ${ }^{11}$ A single dimension of disease severity may be insufficient to accurately reflect the relationship between GERD and COPD, which may require serial measures of lung function over time.

\section{Interaction between GERD and acute exacerbations of COPD}

A large proportion of health care expenditure is related to hospital costs for those admitted with an acute exacerbation of COPD (AECOPD), ${ }^{3,108}$ and prompt intervention is critical in preventing hospital admissions. ${ }^{4}$ A systematic review and meta-analyses of seven observational studies over varying 
durations of follow-up (12-18 months) found the presence of GERD to be associated with a greater risk of experiencing an AECOPD (risk ratio 7.57 [95\% CI 3.84-14.94]). ${ }^{109}$ More recent studies outlined in Table 2 have consistently demonstrated this positive relationship and have noted a higher rate of hospitalization or emergency room visits ${ }^{52,54,55,57,59,60,79,83,110-113}$ among the GERD population. This is consistent with a defined phenotype for patients with COPD who experience frequent AECOPD (two per year), with GERD as an independent predictor. ${ }^{113}$ Studies with a 5-year follow-up found that those who experience both nocturnal and daytime symptoms experienced more exacerbations, with a higher risk in those who did not use regular acid inhibitory treatment (HR 2.7 [95\% CI 1.3-5.4]). ${ }^{113}$

Establishing the precise nature of the relationship between AECOPD and GERD is challenging. Individuals with COPD often demonstrate lower airway bacterial colonization, which may increase their susceptibility to inflammation and infection. ${ }^{114}$ GERD may increase this bacterial load in the lower airways and thereby increase the risk of exacerbations. ${ }^{83}$ With increased pneumonia and wheezing in those with GERD symptoms, ${ }^{53}$ it might be that recurrent aspiration contributes to pneumonia. If GERD is an independent predictor of AECOPD (independent of respiratory infection, degree of airway obstruction, heart failure, cardiac medications, poor adherence to medical therapy, and older age), ${ }^{54,109,112}$ then it may represent a modifiable risk factor.

\section{Impact on quality of life}

Comorbidities in COPD may exert influence on healthrelated quality of life (HRQOL). When GERD was defined by esophageal $\mathrm{pH}$ monitoring, it had only a minimal impact on disease-specific HRQOL among those with moderate to severe COPD,${ }^{11,115}$ an observation confirmed using GERDspecific questionnaires. ${ }^{15}$ However, some studies with a greater sample size have reported a poorer HRQOL reflected in disease-specific and generic questionnaires ${ }^{53,57}$ as well as greater levels of anxiety and depression. ${ }^{96}$ In those aged over 65 years, GERD was associated with a poorer perception of physical health and higher rates of depression and anxiety. ${ }^{116}$

\section{Cost consequences of GERD in COPD}

A substantial proportion of the economic burden associated with COPD is from hospitalization secondary to an acute exacerbation. ${ }^{108,117}$ According to a retrospective cost study of 2,461 individuals aged $>65$ years, ${ }^{116}$ in the $29 \%$ who had coexisting COPD and GERD, the annual Medicare cost was

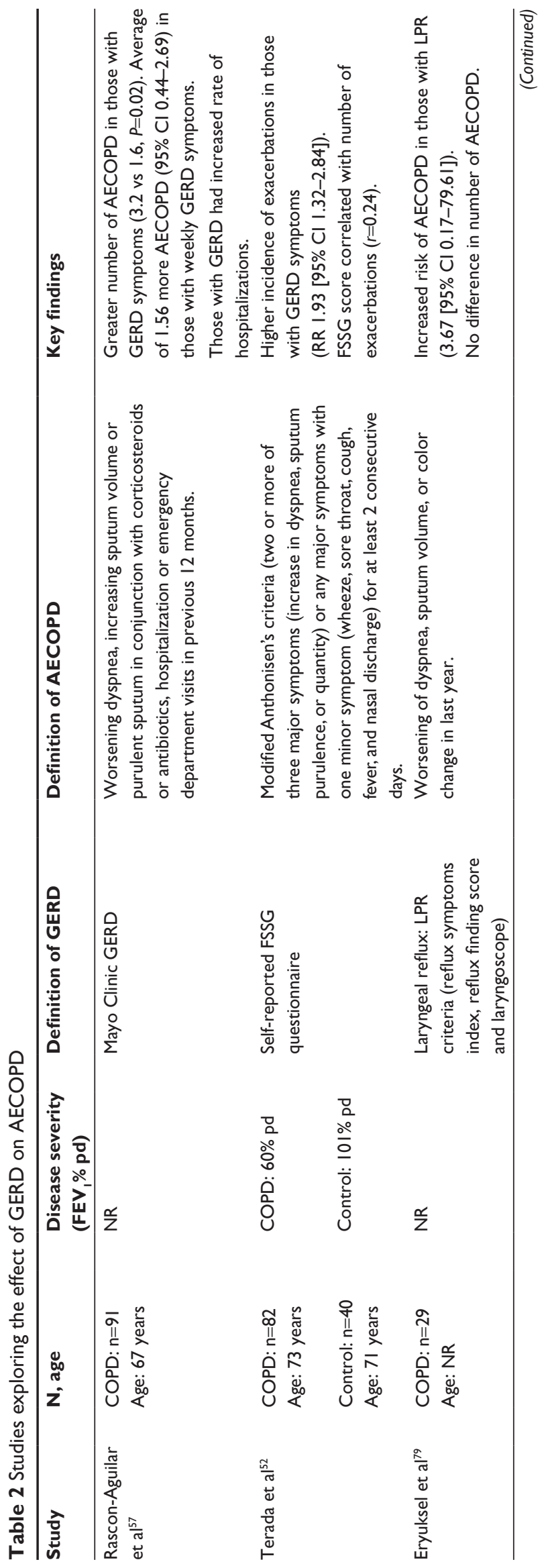




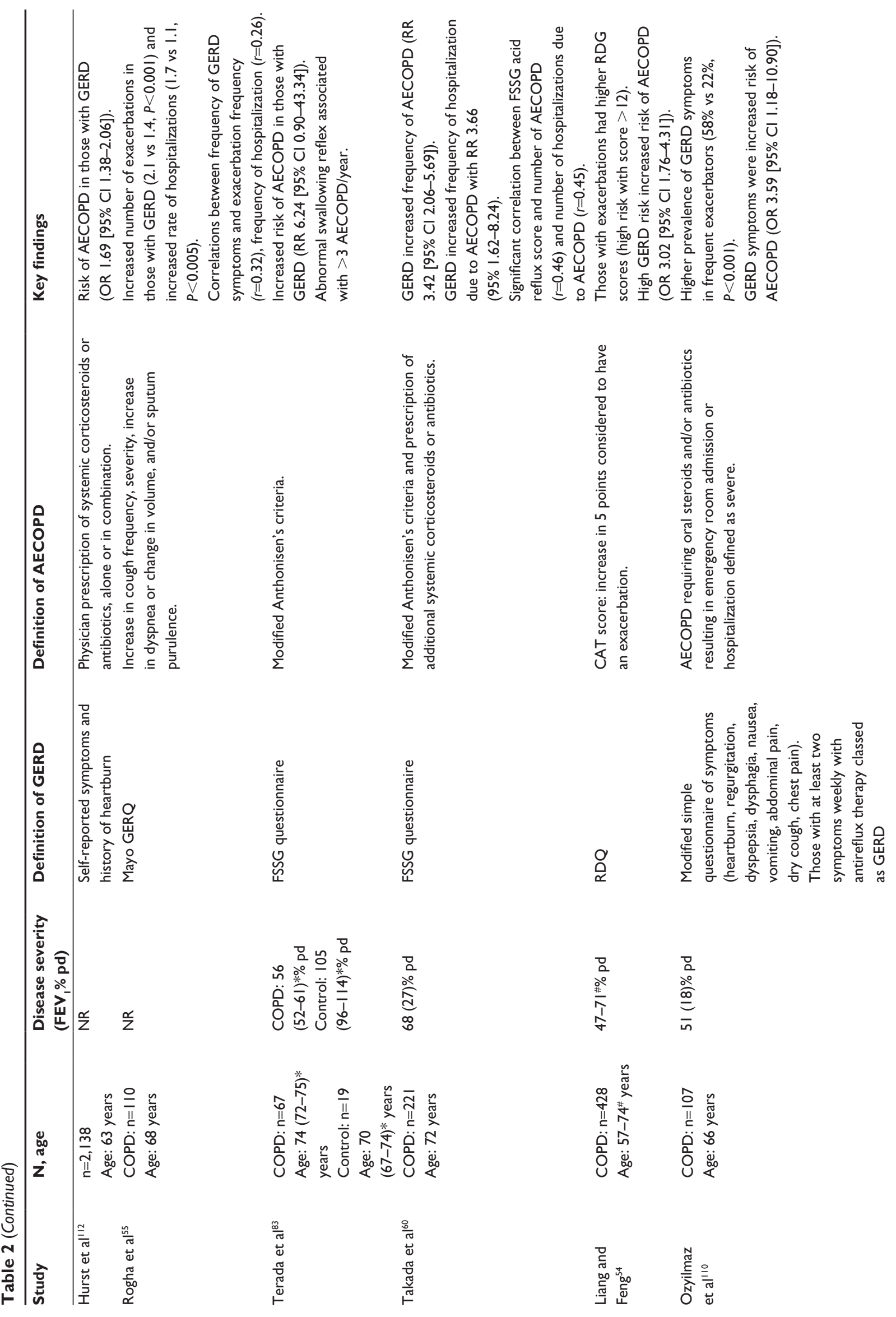




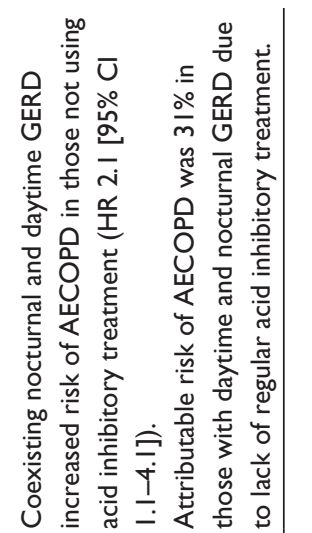

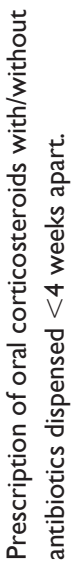

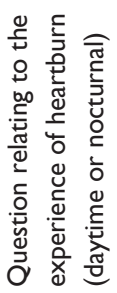

$\stackrel{\alpha}{z}$

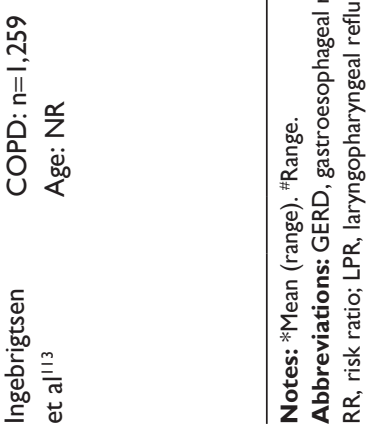

\$US36,793 per patient per year compared to US\$24,722 for those without GERD. ${ }^{116}$ This $36 \%$ increase in costs was attributed to hospitalization for AECOPD. Although specific direct and indirect costs are not yet available, the economic burden appears to be heightened for those with COPD in whom GERD is a comorbidity.

\section{Treatment of GERD}

Lifestyle modification and medical and surgical management have all been used to treat GERD. Suggestions for minimizing the risk of GERD include weight loss, avoidance of late-night meals, and specific food and drink that might aggravate reflux by relaxing the LES. ${ }^{21}$ Altered posture, including adapting a semirecumbent posture when sleeping and avoiding sleeping on the left $\operatorname{side}^{21}$ have also been suggested. ${ }^{38}$ Stress reduction has also been associated with symptom improvement. ${ }^{21}$ These broad recommendations also apply to individuals without $\mathrm{COPD}^{38}$ and are generally recommended as first-line management.

Pharmacologic management includes antacids, histamine ${ }_{2}-$ receptor antagonists $\left(\mathrm{H}_{2}-\mathrm{RA}\right)$, and proton pump inhibitor (PPI) therapy, ${ }^{21}$ as determined by the severity of GERD. There have been few studies of antireflux therapy specifically for those with COPD (Table 3). In a 12-month trial of 100 older patients with GERD, PPI therapy reduced the frequency of AECOPD and common colds compared to usual care. ${ }^{118}$ Improvement in symptoms of laryngopharyngeal reflux, GERD, and respiratory symptoms in individuals with COPD has been found with a combined approach of $\mathrm{H}_{2}-\mathrm{RA}$ and PPI therapy in some studies. ${ }^{12,79}$ Although several studies reported on the prescription of antireflux medication in COPD, they did not report on the impact of therapy on lung function. ${ }^{12,56,57}$ Therefore, the effects of pharmacological management of GERD on lung function, the co-occurrence of respiratory and GERD symptoms, and the use of respiratory medications remain to be clarified. The persistence of symptoms despite antireflux therapy suggests that acid reflux may not always be the primary cause; ${ }^{119}$ this pharmacological approach does not target nonacid or weakly acidic reflux. Surgical management, with a Nissen Fundoplication, has been successfully applied to patients with severe lung disease, including COPD, awaiting transplantation, ${ }^{120-122}$ with reductions in symptoms of GERD as well as of lung disease ${ }^{123}$ and improved lung function in the small group of individuals with COPD. ${ }^{120-122}$ Antireflux surgery is not widely used in COPD but should be considered when medical management fails, especially when GERD remains severe in individuals with COPD at risk of respiratory deterioration. 
Table 3 Effects of medical and surgical treatment on GERD in COPD

\begin{tabular}{|c|c|c|c|}
\hline Study & $\mathbf{N}$ & Treatment approach & Effects of treatment \\
\hline \multicolumn{4}{|l|}{ Medical therapy } \\
\hline \multirow[t]{4}{*}{ Mokhlesi et a $\left.\right|^{12}$} & 100 & Antireflux therapy (duration not specified) & Significant respiratory and GER symptoms in \\
\hline & & Antacids ( $43 \%$ of participants) & $9 \%$ of patients, despite $\mathrm{H}_{2}-\mathrm{RA}$ and PPI therapy. \\
\hline & & PPI ( $28 \%$ of participants) & Resolution of GER symptoms and chronic \\
\hline & & $\mathrm{H}_{2}-\mathrm{RA}$ ( $6 \%$ of participants) & cough in $2 \%$ of patients, without change in PFTs. \\
\hline \multirow[t]{4}{*}{ Kempainen et $\mathrm{a}^{56}$} & 42 & Antireflux therapy & NR. \\
\hline & & (duration not specified) & \\
\hline & & PPI (29\% of participants) & \\
\hline & & $\mathrm{H}_{2}-\mathrm{RA}$ ( $2 \%$ of participants) & \\
\hline \multirow[t]{7}{*}{ Rascon-Aguilar $^{57}$} & 91 & Antireflux therapy & NR. \\
\hline & & (duration not specified) & \\
\hline & & Antacids ( $51 \%$ of participants) & \\
\hline & & $\mathrm{H}_{2}-\mathrm{RA}$ ( $22 \%$ of participants) & \\
\hline & & PPI ( $38 \%$ of participants) & \\
\hline & & $34 \%$ receiving a combination of at least two & \\
\hline & & types of medication & \\
\hline \multirow[t]{11}{*}{ Sasaki et al ${ }^{118}$} & 100 & Antireflux therapy (I2 months), Comparison & Fewer exacerbations with PPI over 12 months \\
\hline & & of treatment (PPI therapy) vs usual care & compared to control ( 0.34 vs I.I8, $P=0.03)$ \\
\hline & & (bronchodilator therapy, smoking cessation) & fewer patients in the PPI group experienced \\
\hline & & PPI therapy & COPD exacerbations more than once ( $24 \%$ vs \\
\hline & & & $52 \% ; P<0.004)$ \\
\hline & & & Trend toward fewer common colds ( 1.22 \\
\hline & & & vs 2.04) and less frequent common colds \\
\hline & & & ( $>3$ per year) with PPI therapy compared to \\
\hline & & & control. \\
\hline & & & PPI therapy independently reduced risk of \\
\hline & & & $\begin{array}{l}\text { exacerbation of COPD (OR } 0.23[95 \% \mathrm{Cl} \\
0.08-0.62] \text { ). }\end{array}$ \\
\hline \multirow[t]{4}{*}{ Eryuksel et al ${ }^{79}$} & 30 & Antireflux therapy (2 months) & Reduced COPD symptoms $(P<0.0 \mathrm{I})$ \\
\hline & & PPI therapy & reduction in laryngopharyngeal reflux \\
\hline & & & symptoms $(P<0.0 \mathrm{I})$, and improved laryngeal \\
\hline & & & examinations $(P<0.00 \mathrm{I})$ \\
\hline \multirow[t]{3}{*}{ Ingebrigtsen et al ${ }^{1 / 3}$} & 1,259 & Regular use of acid inhibitory therapy (59\%) & NR. \\
\hline & & in those with nighttime and/or daytime & \\
\hline & & GERD & \\
\hline \multicolumn{4}{|l|}{ Surgical treatment } \\
\hline \multirow[t]{3}{*}{ Hartwig et al ${ }^{120}$} & 20 & Following bilateral lung transplantation, & FEV , greater at I-year with fundoplication \\
\hline & & Nissen fundoplication ( $<365$ days post- & compared to no fundoplication $(8.8 \%$ \\
\hline & & transplant) undertaken in selected patients & difference). \\
\hline \multirow[t]{3}{*}{ Hoppo et al ${ }^{122}$} & 11 & Pretransplant Nissen fundoplication & Improved $\mathrm{FEV}_{\text {, and }} \mathrm{FVC} \%$ predicted in overall \\
\hline & & & group (separate outcomes for COPD not \\
\hline & & & reported). \\
\hline
\end{tabular}

Abbreviations: GER, gastroesophageal reflux; $\mathrm{H}_{2}-\mathrm{RA}, \mathrm{H}_{2}$ receptor antagonist; PPI, proton pump inhibitor; PFTs, pulmonary function tests; NR, not reported; OR, odds ratio; $\mathrm{Cl}$, confidence interval; GERD, gastroesophageal reflux disease; $\mathrm{FEV}_{1}$, forced expiratory volume in I second; FVC, forced vital capacity.

\section{Conclusion}

GERD is a common comorbidity in those with COPD and has a variety of clinical presentations. The index of clinical suspicion should remain high, and objective measures should be used for diagnostic confirmation. The best way to identify pulmonary microaspiration of gastric contents in COPD remains to be established. The presence of GERD appears to increase the risk of an AECOPD and may affect disease progression. Although the co-occurrence of these two common conditions may be associated with increased health care utilization, treatment approaches that have been successfully applied in individuals with GERD without COPD also appear to be effective in the presence of COPD.

\section{Disclosure}

The authors report no disclosures or conflicts of interest in this work. 


\section{References}

1. Global Initiative for Chronic Obstructive Pulmonary Disease [homepage on the Internet]. Global Strategy for the Diagnosis, Management and Prevention of Chronic Obstructive Pulmonary Disease; 2014. Available from: http://www.goldcopd. Accessed 24 February, 2015.

2. Seemungal T, Donaldson G, Paul E, Bestall J, Jeffries D, Wedzicha J. Effect of exacerbation on quality of life in patients with chronic obstructive pulmonary disease. Am J Respir Crit Care Med. 1998;157: 1418-1422.

3. Vos T, Flaxman A, Naghavi M. Years lived with disability (YLDs) for 1160 sequelae of 289 diseases and injuries 1990-2010: a systematic analysis for the Global Burden of Disease Study 2010. Lancet. 2012;380:2163-2196.

4. Seemungal T, Donaldson G, Bhowmik A, Jeffries DJ, Wedzicha JA. Time course and recovery of exacerbations in patients with chronic obstructive pulmonary disease. Am J Respir Crit Care Med. 2000;161: 1608-1613.

5. Rycroft C, Heyes A, Lanza L, Becker K. Epidemiology of chronic obstructive pulmonary disease: a literature review. Int J Chron Obstruct Pulmon Dis. 2012;7:457-494.

6. Vakil N, Van Zanten S, Kahrilas PJ, Dent J, Jones R. The Montreal definition and classification of gastroesophageal reflux disease: a global evidence-based consensus. Am J Gastroenterol. 2006;101: 1900-1920.

7. El-Serag H, Sweet S, Winchester C, Dent J. Update on the epidemiology of gastro-oesophageal disease: a systematic review. Gut. 2014; 63(6):871-880.

8. Sifrim D, Holloway R, Silny J. Acid, nonacid, and gas reflux in patients with gastroesophageal reflux disease during ambulatory 24 -hour $\mathrm{pH}$-impedance recordings. Gastroenterology. 2001;120(7):1588-1598.

9. Ducoloné A, Vandevenne A, Jouin H, et al. Gastroesophageal reflux in patients with asthma and chronic bronchitis. Am Rev Respir Dis. 1987; 135:327-332.

10. Sweet M, Patti M, Hoopes C, Hayes SR, Golden JA. Gastro-oesophageal reflux and aspiration in patients with advanced lung disease. Thorax. 2009;64:167-173.

11. Casanova C, Baudet JS, del Valle Velasco M, et al. Increased gastrooesophageal reflux disease in patients with severe COPD. Eur Respir J. 2004;23:841-845.

12. Mokhlesi B, Morris A, Huang C-F, Curcio A, Barrett T, Kamp D. Increased prevalence of gastroesophageal reflux symptoms in patients with COPD. Chest. 2001;119(4):1043-1048.

13. Mittal R, Holloway R, Penagini R, Blackshaw L, Dent J. Transient lower esophageal sphincter relaxation. Gastroenterology. 1995;109:601-610.

14. Schoeman MN, Tippett MD, Akkermans LM, Dent J, Holloway RH. Mechanisms of gastroesophageal reflux in ambulant healthy human subjects. Gastroenterology. 1995;108(1):83-91.

15. Mittal R, McCallum R. Characteristics and frequency of transient relaxations of the lower esophageal sphincter in patients with reflux esophagitis. Gastroenterology. 1988;95:593-599.

16. Dent J, Holloway R, Toouli J, Dodds W. Mechanisms of lower oesophageal sphincter incompetence in patients with symptomatic gastro-oesophageal reflux. Gut. 1988;29:1020-1028.

17. Chandrasoma P, DeMeester TR. GERD: Reflux to Esophageal Adenocarcinoma. San Diego: Elsevier; 2006.

18. Vandenplas Y, Hassall E. Mechanisms of gastroesophageal reflux and gastroesophageal reflux disease. J Pediatr Gastroenterol Nutr. 2002;35(2):119-136

19. Richter J. Gastroesophageal reflux disease. In: Yamada T, editor. Textbook of Gastroenterology. Philadelphia: Lippincott Williams and Williams; 2003:1196-1224.

20. Kahrilas P, Dodds WJ, Hogan W. Effect of peristaltic dysfunction on esophageal volume clearance. Gastroenterology. 1988;94:73-80.

21. Katz PO, Gerson LB, Vela MF. Corrigendum: guidelines for the diagnosis and management of gastroesophageal reflux disease. Am J Gastroenterol. 2013;108:308-328.
22. Klauser A, Schindlbeck N, Muller-Lissner S. Symptoms in gastrooesophageal reflux disease. Lancet. 1990;335:205-208.

23. Locke GI, Talley N, Fett S. Prevalence and clinical spectrum of gastroesophageal reflux: a population-based study in Olmsted County, Minnesota. Gastroenterology. 1997;112:1448-1456.

24. Flook N, Jones R, Vakil N. Approach to gastroesophageal reflux disease in primary care. Putting the Montreal definition into practice. Can Fam Physician. 2008:54:701-705.

25. Stanghellini V, Armstrong D, Monnikes H, Bardhans K. Systematic review: do we need a new gastro-oesophageal reflux disease questionnaire? Aliment Pharmacol Ther. 2004;19:463-489.

26. Fraser A, Delaney B, Moayyedi P. Symptom-based outcome measures for dyspepsia and GERD trials: a systematic review. Am J Gastroenterol. 2005;100:442-452.

27. Juul-Hansen P, Rydning A, Jackobsen C, Hansen T. High dose proton-pump inhibitors as a diagnostic test of gastro-oesophageal reflux disease in endoscopic-negative patients. Scand J Gastroenterol. 2001;36:806-810.

28. Fass R, Ofman J. Gastroesophageal reflux disease - should we adopt a new conceptual framework? Am J Gastroenterol. 2002;97(8): 1901-1909.

29. Richter J. Severe reflux esophagitis. Gastroenterol Clin North Am. 1994;4:677.

30. DeMeester TR, Wang CI, Wernly JA, et al. Techniques, indications and clinical use of 24 hour oesophageal monitoring. J Thorac Cardiovasc Surg. 1980;79:656-670.

31. Jamieson JR, Stein HJ, DeMeester TR, et al. Ambulatory 24-pH esophageal $\mathrm{pH}$ monitoring: normal values, optimal thresholds, specificity, sensitivity and reproducibility. Am J Gastroenterol. 1992;87(9): $1102-1111$.

32. Streets C, DeMeester T. Ambulatory 24-hour esophageal pH monitoring: why, when and what to do. J Clin Gastroenterol. 2003; $37(1): 14-22$

33. Johnsson F, Joelsson B, Isberg P-E. Ambulatory 24 hour intraesophageal $\mathrm{pH}$-monitoring in the diagnosis of gastroesophageal reflux disease. Gut. 1987;28:1145-1150.

34. Dobhan R, Castell D. Normal and abnormal proximal esophageal acid exposure: results of ambulatory dual-probe $\mathrm{pH}$ monitoring. $\mathrm{Am}$ $J$ Gastroenterol. 1993;88(1):25-29.

35. Johnson L, DeMeester T. Twenty-four $\mathrm{pH}$ monitoring of the distal esophagus: a quantitative measure of gastroesophageal reflux. Am J Gastroenterol. 1974;62:325-332.

36. Vaezi M, Schroeder P, Richter J. Reproducibility of proximal probe $\mathrm{pH}$ parameters in 24-hour ambulatory $\mathrm{pH}$ monitoring. Am J Gastroenterol. 1997;92:825-829.

37. Emerenziani S, Ribolsi M, Pasqualetti P, Cicala M. Proximal reflux sensitivity: measurement of acid exposure of proximal esophagus: a better tool for diagnosing non-erosive reflux disease. Neurogastroenterol Motil. 2011;23(711):e324.

38. Katz PO, Matheus T. Telemetry capsule for ambulatory $\mathrm{pH}$ monitoring: is it time for a change? Am J Gastroenterol. 2008;103: 2986-2987.

39. Shay S, Bomeli S, Richter J. Multichannel intraluminal impedance accurately detects fasting, recumbent reflux events and their clearing. Am J Physiol Gastrointest Liver Physiol. 2002;283:376-383.

40. Sifrim D, Silny J, Holloway R, Janssens J. Patterns of gas and liquid reflux during transient lower esophageal sphincter relaxation. A study using intraluminal electrical impedance. Gut. 1999;44:47-54.

41. D’Ovidio F, Singer LG, Hadjiliadis D, et al. Prevalence of gastroesophageal reflux in end-stage lung disease candidates for lung transplant. Ann Thorac Surg. 2005;80:1254-1261.

42. Sweet MP, Herbella FA, Leard L, et al. The prevalence of distal and proximal gastroesophageal reflux in patients awaiting lung transplantation. Ann Surg. 2006;244(4):491-497.

43. Sole ML, Conrad J, Bennett M, et al. Pepsin and amylase in oral and tracheal secretions. A pilot study. Am J Crit Care. 2014;23(4): $334-338$. 
44. Potluri S, Friedenberg F, Parkman HP, et al. Comparison of a salivary/ sputum pepsin assay with 24-hour esophageal $\mathrm{pH}$ monitoring for detection of gastric reflux into the proximal esophagus, oropharynx and lung. Dig Dis Sci. 2003;48(9):1813-1817.

45. Ward C, Forrest IA, Brownlee IA, et al. Pepsin like activity in bronchoalveolar lavage fluid is suggestive of gastric aspiration in lung allografts. Thorax. 2005;60:872-874.

46. Stovold R, Forrest IA, Corris PA, et al. Pepsin, a biomarker of gastric aspiration in lung allografts. A putative association with rejection. Am J Respir Crit Care Med. 2007;175:1298-1303.

47. Blondeau K, Mertens V, Vanaudenaerde BA, et al. Gastro-oesophageal reflux and gastric aspiration in lung transplant patients with or without chronic rejection. Eur Respir J. 2008;31:707-713.

48. Reder N, Davis C, Kovacs E, Fisichella P. The diagnostic value of gastroesophageal reflux disease (GERD) symptoms and detection of pepsin and bile acids in bronchoalveolar lavage fluid and exhaled breath condensate for identifying lung transplantation patients with GERDinduced aspiration. Surg Endosc. 2014;28(6):1794-1800.

49. Lee AL, Button B, Denehy L, et al. Proximal and distal gastro-oesophageal reflux in chronic obstructive pulmonary disease and bronchiectasis. Respirology. 2014;19(2):211-217.

50. Timms C, Thomas P, Yates D. Detection of gastro-oesophageal reflux disease (GORD) in patients with obstructive lung disease using exhaled breath profiling. J Breath Res. 2012;6:016003.

51. Kostikas K, Papatheodorou G, Ganas K, Psathakis K, Panagou P, Loukides S. pH in expired breath condensate of patients with inflammatory airway diseases. Am J Respir Crit Care Med. 2002;165(10):1364-1370.

52. Terada K, Muro S, Sato S, et al. Impact of gastro-oesophageal reflux disease symptoms on chronic obstructive pulmonary disease exacerbation. Thorax. 2008;63:951-955.

53. Martinez CH, Okajima Y, Murray S, et al; COPDGene Investigators. Impact of self-reported gastroesophageal reflux disease in subjects from COPD Gene cohort. Respir Res. 2014;15:62.

54. Liang B-M, Feng Y-L. Association of gastroesophageal reflux disease symptoms with stable chronic obstructive pulmonary disease. Lung. 2012;190:277-282.

55. Rogha M, Behravesh B, Pourmoghaddas Z. Association of gastroesophageal reflux disease symptoms with exacerbations of chronic obstructive pulmonary disease. J Gastrointest Liver Dis. 2010;19(3):253-256.

56. Kempainen R, Savik K, Whelan T, Dunitz J, Herrington C, Billings J. High prevalence of proximal and distal gastroesophageal reflux disease in advanced COPD. Chest. 2007;131:1666-1671.

57. Rascon-Aguilar IE, Pamer M, Wludyka P, et al. Role of gastroesophageal reflux symptoms in exacerbations of COPD. Chest. 2006; 130:1096-1101.

58. Bor S, Kitapcioglu G, Solak Z, Ertilav M, Erdinc M. Prevalence of gastroesophageal reflux disease in patients with asthma and chronic obstructive pulmonary disease. J Gastroenterol Hepatol. 2010;25:309-313.

59. Shimizu Y, Dobashi K, Kusano M, Mori M. Different gastroesophageal reflux symptoms of middle-aged to elderly asthma and chronic objective pulmonary disease patients. J Clin Biochem Nutr. 2011;50(2):169-175.

60. Takada K, Matsumoto S, Kojima E, et al. Prospective evaluation of the relationship between acute exacerbations of COPD and gastroesophageal reflux disease diagnosed by questionnaire. Respir Med. 2011;105:1531-1536

61. Phulpoto M, Ozyyum S, Rizvi N, Khuhaware S. Proportion of gastroesophageal symptoms in patients with chronic obstructive pulmonary disease. J Pak Med Assoc. 2005;55:276-279.

62. Kamble N, Khan N, Kumar N, Nayak H, Daga M. Study of gastro-oesophageal reflux disease in patients with mild-to-moderate chronic obstructive pulmonary disease in India. Respirology. 2013;18:463-467.

63. Andersen L, Jensen G. Prevalence of benign oesophageal disease in the Danish population with special reference to pulmonary disease. J Intern Med. 1989;225:393-401.

64. Gadel AA, Mostafa M, Younis A, Haleem M. Esophageal motility pattern and gastroesophageal reflux in chronic obstructive pulmonary disease. Hepatogastroenterology. 2012;59(120):2498-2502.
65. Weusten B, Akkermans L, vanBerge-Henegouwen GP, Smout AJ. Spatiotemporal characteristics of physiological gastroesophageal reflux. Am J Physiol. 1994;266:G357-G362.

66. DeMeester T, Johnson L, Joseph G, Toscano M, Hall A, Skinner D. Patterns of gastroesophageal reflux in health and disease. Ann Surg. 1976;184(4):459-470.

67. Dent J, El-Serag H, Wallander M, Johansson S. Epidemiology of gastro-oesophageal reflux disease: a systematic review. Gut. 2005;54: 710-717.

68. Areias V, Carreira S, Anciaes M, Pinto P, Barbara C. Co-morbidities in patients with gold stage 4 chronic obstructive pulmonary disease. Rev Port Pneumol. 2014;20(1):5-11.

69. McColl E. Best practice in symptom assessment: a review. Gut. 2004;53(suppl 4):49-54.

70. El-Serag H, Sonnenberg A. Comorbid occurrence of laryngeal or pulmonary disease with esophagitis in United States Military Veterans. Gastroenterology. 1997;113:755-760.

71. Garcia Rodriguez L, Ruigomez A, Martin-merino E, Johansson S, Wallander M. Relationship between gastroesophageal reflux disease and COPD in UK primary care. Chest. 2008;134(6):1223-1230.

72. Pandolfino JE, Kahrilas PJ. Smoking and gastro-esophageal reflux disease. Eur J Gastroenterol Hepatol. 2000;12:837-842.

73. Kadakia SC, Kikendall JW, Maydonovitch C, Johnson LF. Effect of cigarette smoking on gastroesophageal reflux measured by 24-h ambulatory esophageal pH monitoring. Am J Gastroenterol. 1995;90:1785-1790.

74. Kim S, Lee J, Sim Y, Ryu Y, Chang J. Prevalence and risk factors for reflux esophagitis in patients with chronic obstructive pulmonary disease. Korean J Intern Med. 2014;29:466-473.

75. Hill C, Jones R. Systematic review: the epidemiology of gastro-oesophageal reflux disease in primary care, using the UK general practice research database. Aliment Pharmacol Ther. 2009;29:470-480.

76. Rahman I. Oxidative stress in pathogenesis of chronic obstructive pulmonary disease: cellular and molecular mechanisms. Cell Biochem Biophys. 2005;43:167-188.

77. Farrell S, McMaster C, Gibson D, Shields M, McCallion W. Pepsin in bronchoalveolar lavage fluid: a specific and sensitive method of diagnosing gastro-oesophageal reflux-related pulmonary aspiration. J Pediatr Surg. 2006;41:289-293.

78. Pauwels A, Decraene A, Blondeau K, et al. Bile acids in sputum and increased airway inflammation in patients with cystic fibrosis. Chest. 2012;141(6):1568-1574.

79. Eryuksel E, Dogan M, Olgun S, Kocak I, Celikel T. Incidence and treatment results of laryngopharyngeal reflux in chronic obstructive pulmonary disease. Eur Arch Otorhinolaryngol. 2009;266(8):1267-1271.

80. Lee A, Button B, Denehy L, et al. Exhaled breath condensate pepsin: potential noninvasive test for gastroesophageal reflux in COPD and bronchiectasis. Respir Care. 2015;60(2):244-250.

81. Orr W, Elsenbruch S, Harnish M, Johnson L. Proximal migration of esophageal acid perfusions during waking and sleep. Am J Gastroenterol. 2000;95:37-42.

82. Fortunato G, Machado M, Andrade C, Felicetti J, Camargo J, Cardoso P. Prevalence of gastroesophageal reflux in lung transplant candidates with advanced lung disease. J Bras Pneumol. 2008;34(10):772-778.

83. Terada K, Muro S, Ohara T, et al. Abnormal swallowing reflex and COPD exacerbations. Chest. 2010;137(2):326-332.

84. Teramoto S, Kume H, Ouchi Y. Altered swallowing physiology and aspiration in COPD. Chest. 2002;122(3):1104-1105.

85. Gross R, Atwood DJ, Ross S, Olszewski J, Eichhorn K. The coordination between breathing and swallowing in chronic obstructive pulmonary disease. Am J Respir Crit Care Med. 2009;179(7):559-565.

86. Mokhlesi B, Logemann JA, Rademaker AW, Stangl CA, Corbridge TC. Oropharyngeal deglutition in stable COPD. Chest. 2002;121(2):361-369.

87. Mokhlesi B. Clinical implications of gastroesophageal reflux disease and swallowing dysfunction in COPD. Am J Respir Med. 2003;2(2):117-121.

88. Pauwels A, Blondeau K, Dupont L, Sifrim D. Mechanisms of increased gastroesophageal reflux in patients with cystic fibrosis. Am J Gastroenterol. 2012;107(9):1346-1353. 
89. Turbyville J. Applying principles of physics to the airway to help explain the relationship between asthma and gastroesophageal reflux. Med Hypotheses. 2010;74:1075-1080.

90. Field S, Underwood M, Brant R, Cowie R. Prevalence of gastroesophageal reflux symptoms in asthma. Chest. 1996;109:316-322.

91. Naliboff BD, Mayer M, Fass R, et al. The effect of life stress on symptoms of heartburn. Psychosom Med. 2004;66(3):426-434.

92. Stein M, Towner T, Weber R. The effect of theophylline on the lower esophageal sphincter pressure. Ann Allergy. 1980;45:238.

93. Crowell M, Zayat E, Lacy B. The effects of an inhaled $\mathrm{B}_{2}$-adrenergic agonist on lower esophageal function: a dose-response study. Chest. 2001;121:1024-1027.

94. Kim J, Lee JH, Kim Y, et al. Association between chronic obstructive pulmonary disease and gastroesophageal reflux disease: a national cross-sectional cohort study. BMC Pulmon Med. 2013;13:51.

95. Ruzkowski C, Sanowski R, Austin J, Rohwedder JJ, Waring JP. The effects of inhaled albuterol and oral theophylline on gastroesophageal reflux in patients with gastroesophageal reflux disease and obstructive lung disease. Arch Intern Med. 1992;152(4):783-785.

96. Niklasson A, Strid H, Simren M, Engstrom C-P, Bjornsson E. Prevalence of gastrointestinal symptoms in patients with chronic obstructive pulmonary disease. Eur J Gastroenterol Hepatol. 2008;20(4):335-341.

97. Sontag S, O’Connell S, Khandelwal S, Miller T, Nemchausky B, Schnell T. Most asthmatics have gastroesophageal reflux with or without bronchodilator therapy. Gastroenterology. 1990;99:613-620.

98. Hubert D, Gaudric M, Guerre J, Lockhart A, Marsac J. Effect of theophylline on gastroesophageal reflux in patients with asthma. J Allergy Clin Immunol. 1988;81:1168-1174.

99. Kulig M, Nocon M, Vieth M, et al. Risk factors of gastroesophageal reflux disease: methodology and first epidemiological results of the ProGERD study. J Clin Epidemiol. 2004;57:580-589.

100. Locke R, Talley N, Fett S, Zinsmeister A, Melton J. Risk factors associated with symptoms of gastroesophageal reflux. Am J Med. 1999;106: 642-649.

101. Dore M, Maragkoudakis E, Fraley K, et al. Diet, lifestyle and gender in gastro-esophageal reflux disease. Dig Dis Sci. 2008;53(8):2017-2032.

102. Corley D, Kubo A. Body mass index and gastroesophageal reflux disease: a systematic review and meta-analysis. Am J Gastroenterol. 2006;108:2619-2628.

103. Demeter P, Pap A. The relationship between gastroesophageal reflux disease and obstructive sleep apnea. J Gastroenterol. 2004;39:815-820.

104. Zagari RM, Fuccio L, Wallander MA, et al. Gastro-oesophageal reflux symptoms, oesophagitis and Barrett's oesophagus in the general population: the Loiano-Monghidoro study. Gut. 2008;57(10):1354-1359.

105. Harding S. GERD, airway disease and the mechanisms of interaction In: Stein M, editor. Gastroesophageal Reflux Disease and Airway Disease. New York: Marcel Dekker Inc; 1999:162-163.

106. Canning B, Mazzone S. Reflex mechanisms in gastroesophageal reflux disease and asthma. Am J Med. 2003;115:45S-48S.

107. Orr W, Shamma-Othman Z, Allen M, Robinson M. Esophageal function and gastroesophageal reflux during sleep and waking in patients with chronic obstructive pulmonary disease. Chest. 1992;101:1521-1525.

108. Guarascio A, Ray S, Finch C, Self T. The clinical and economic burden of chronic obstructive pulmonary disease in the USA. Clinicoeconom Outcomes Res. 2013;5:235-245.
109. Sakae T, Pizzichini M, Teixeira P, de Silva R, Trevisol D, Pizzichini E. Exacerbations of COPD and symptoms of gastroesophageal reflux: a systematic review and meta-analysis. J Bras Pneumol. 2013;39(3): 259-271.

110. Ozyilmaz E, Kokturk N, Teksut G, Tatlicioglu T. Unsuspected risk factors of frequent exacerbations requiring hospital admission in chronic obstructive pulmonary disease. Inter J Clin Pract. 2013; 67:691-697.

111. Lin Y, Tsai C, Chien L, Chiou H, Jeng C. Newly diagnosed gastroesophageal reflux disease increased the risk of acute exacerbations of chronic obstructive pulmonary disease during the first year following diagnosis - a nationwide population-based cohort study. Inter J Clin Pract. 2015;69(3):350-357.

112. Hurst J, Vestbo J, Anzueto A. Susceptibility to exacerbation in chronic obstructive pulmonary disease. N Engl J Med. 2010;363(12) 1128-1138.

113. Ingebrigtsen T, Marott J, Vestbo J, Nordestgaard B, Hallas J, Lange P Gastroesophageal reflux disease and exacerbations in chronic obstructive pulmonary disease. Respirology. 2015;20:101-107.

114. Pacheco-Galvan A, Hart S, Morice A. Relationship between gastrooesophageal reflux and airway diseases: the airway reflux paradigm. Arch Bronchoneumol. 2011;47:195-203.

115. Lee AL. Gastro-oesophageal reflux in chronic obstructive pulmonary disease and bronchiectasis, $\mathrm{PhD}$ Thesis. Melbourne: The University of Melbourne; 2009.

116. Ajmera M, Raval A, Shen C, Sambamoorthi U. Explaining the increased health care expenditures associated with gastroesophageal reflux disease among elderly Medicare beneficiaries with chronic obstructive pulmonary disease: a cost-decomposition analysis. Int J Chron Obstruct Pulmon Dis. 2014;9:339-348.

117. National Institute for Health and Care Excellence. Chronic Obstructive Pulmonary Disease. Management of Chronic Obstructive Pulmonary Disease in Adults in Primary and Secondary Care; 2010. Available from: https://www.nice.org.uk/guidance/cg101/chapter/1-guidance. Accessed 24 February, 2015.

118. Sasaki T, Nakayama K, Yasuda H, et al. A randomised, single-blind study of lansoprazole for the prevention of exacerbations of chronic obstructive pulmonary disease in older patients. J Am Geriatr Soc. 2009;57(8):1453-1457.

119. Storr MA. What is nonacid reflux disease? Can J Gastroenterol. 2011;25(1):35-38.

120. Hartwig MG, Anderson DJ, Onaitis MW, et al. Fundoplication after lung transplantation prevents the allograft dysfunction associated with reflux. Ann Thorac Surg. 2011;92(2):462-468.

121. Gasper WJ, Sweet MP, Hoopes C, et al. Antireflux surgery for patients with end-stage lung disease before and after lung transplantation. Surg Endosc. 2008;22:495-500.

122. Hoppo T, Jarido V, Pennathur A, et al. Antireflux surgery preserves lung function in patients with gastroesophageal reflux disease and end-stage lung disease before and after lung transplantation. Arch Surg. 2011;146(9):1041-1047.

123. Ekstrom T, Johansson K. Effects of anti-reflux surgery on chronic cough and asthma in patients with gastro-oesophageal reflux disease. Respir Med. 2000;94(12):1166-1170.
International Journal of COPD

\section{Publish your work in this journal}

The International Journal of COPD is an international, peer-reviewed journal of therapeutics and pharmacology focusing on concise rapid reporting of clinical studies and reviews in COPD. Special focus is given to the pathophysiological processes underlying the disease, intervention programs, patient focused education, and self management protocols.
Dovepress

This journal is indexed on PubMed Central, MedLine and CAS. The manuscript management system is completely online and includes a very quick and fair peer-review system, which is all easy to use. Visit http://www.dovepress.com/testimonials.php to read real quotes from published authors. 